\title{
Research on the Current Situation and Path of the Local Government's Supervision of Car-Hailing
}

\author{
Di Zhang \\ School of Government Management, Beijing Normal University, Beijing, China \\ Email:1255711450@qq.com
}

How to cite this paper: Zhang, D. (2018) Research on the Current Situation and Path of the Local Government's Supervision of Car-Hailing. American Journal of Industrial and Business Management, 8, 1673-1683. https://doi.org/10.4236/ajibm.2018.87111

Received: June 6, 2018

Accepted: July 6, 2018

Published: July 9, 2018

Copyright $\odot 2018$ by author and Scientific Research Publishing Inc. This work is licensed under the Creative Commons Attribution International License (CC BY 4.0).

http://creativecommons.org/licenses/by/4.0/

\section{(c) (i) Open Access}

\begin{abstract}
With the continuous development of the Internet technology, the launch of the car-hailing has attracted the attention of all sectors of society. As a new mode of travel, car-hailing has the advantages of high timeliness and convenience and has caused a great impact on the traditional taxi industry. In response to the active response to the central government's policy objectives, local governments in China are still faced with multi-dimensional challenges relating to online dating platforms, taxi companies, and private car owners. Therefore, local governments should consider the local economic and social development status, adhere to the central government's legislative authority, adhere to the local government's policy objectives, develop the "government plus enterprise" regulatory model, and strengthen legislation to eliminate the disadvantages of local legislation to deal with issues during the regulatory process.
\end{abstract}

\section{Keywords}

Local Government, Supervision Arbitrage, Government Supervision

\section{Introduction}

In recent years, with the ever-growing "Internet+" technology, not only has it promoted China's economic development, but also provided vital energy for social and economic entities. At the same time, it has also provided a broader platform for all sectors of society. The car-hailing came into being under this background. At present, the appropriation of the network has become the largest capacity addition to public transportation in the daily life of the masses, gradually changing people's travel habits. There is a big difference between the operation 
of the car-hailing and traditional taxis in terms of operating modes and services, which has caused a certain impact on the traditional taxi industry. But it will also have accidents, disputes and other related issues. Therefore, in July 2016, the Ministry of Transport, the Ministry of Public Security, the Ministry of Commerce, and the State Administration for Industry and Commerce jointly passed the Interim Measures for the Administration of Online Booking of Taxi Business Services, which set out clear rules for the management of online travel vehicles. It has promoted the development of standardized car-hailing.

Basing on the theory of policy networks to analyze the current status of car-hailing supervision, and uses social network analysis software to assist in research, and further presenting the status of car-hailing policy activists, and carefully analyzes the interactive relationship between car-hailing policy actors and problems in the interaction process, and put forward corresponding suggestions. This article through the in-depth discussion of the local government's supervision of the car-hailing current situation and the countermeasures to draw the following conclusions: At this stage, the car-hailing policy activists have more conflicts of interests and have not yet formed a stable cooperative relationship. Due to the large number of policy actors involved and the different interests appealed, if there is no fixed communication mechanism and platform cooperation, the local government will be more and more difficult to monitor the car-hailing. Therefore, the local government as a more resourceful member of the network approving actor activist network should take the initiative to play a guiding role, encouraging network approving vehicle actors to participate in the process of formulating car-hailing policies, and focusing on the construction of information and communication platforms. Problems such as publicizing the system and eliminating the drawbacks of local laws and regulations have solved the problem of the local government's supervision of car-hailing。

The paper is divided into six parts: The first part is as an introduction, expounding how the car-hailing has rapidly emerged from the Internet advantage. In the second part, the concept and characteristics of the car-hailing are introduced in detail, and it can be concluded that the car-hailing has received more and more attention because it meets the diverse needs of passengers, realizes resource reconfiguration, and has good service quality. The third part mainly introduces the theoretical basis of the car-hailing, mainly including policy networks theory research. At present, as a new business model, there are still not enough governance precedents for reference. The research at this stage mainly focuses on the government supervision and the legitimacy of car-hailing. The research on the theoretical system of car-hailing policies has not yet formed a system. The fourth part mainly introduces that local governments in China face conflicts of interests in the process of monitoring the car-hailing, including the central government and local governments, local government and car-hailing, local government and taxi companies, local governments and drivers. The conflict of interests among car owner challenges. How the local government finds 
suitable local development strategies, how to control the network about the car platform, how to protect the traditional taxi companies, and the attitude taken by owners of private cars have become problems that local governments urgently need to solve. The fifth part focuses on the proposed countermeasures and suggestions for the management of car-hailing, aiming to further improve the local government's supervision of car-hailing. The final part is the conclusion of the article, including the summary of the research content, the deficiencies of the paper and the outlook of the research field.

\section{The Definition of Car-Hailing}

Car-hailing is an emerging industry in which passengers are free to choose the travel mode based on the data provided by the car-hailing platforms (including the number of vehicles, distance range, and arrival time). "Guidance on Deepening Reform and Further Promoting the Healthy Development of the Taxi Industry (Draft for Solicitation of Opinions)" have defined the car-hailing as "Building a service platform based on internet technology, integrating supply and demand information, and employ qualified vehicles and drivers" [1]. This also clearly categorizes the scope of the car-hailing into the traditional taxi industry, so as to incorporate it into the supervision mechanism of the taxi [2].

As a new mode of transportation, the car-hailing has gradually attracted the attention of the public. It also has the following characteristics.

Firstly, to meet the diverse needs of passengers. Since the Reform and opening, China's political, economic, and cultural development has been improvement. The availability of taxis is undoubtedly a landmark product of our country's transportation progress. With the progress and development of society, traditional taxi drivers have been restricted in many ways by the way of fast travel on the streets and other places. Passengers often face expensive taxis, and being not standard in the taxi industry and taxi drivers' often refusing to take passengers are the human factors that make it difficult to take a taxi. The introduction of the car-hailing platforms not only alleviates the difficulties of passenger cars and expensive taxis, but also introduces special service vehicle types such as tailored taxi service、 ride sharing , fast ride and so on to meet the diversified needs of different passengers, making travel more convenient.

Secondly, implement resource reconfiguration. Because the central government and local governments have strict control over the number of traditional taxis, taxi drivers have higher barriers to entry, and as a result, some people cannot enter the taxi industry. The appearance of the car-hailing will undoubtedly provide some private owners with green access to the market. The car-hailing not only helps private car owners to make profits in addition to their daily work, but also enables some idle people in the society to obtain employment opportunities, relieve employment pressure, increase employment rates, and provide more convenient transportation for urban transport. According to the data from May 4, 2017, starting from the establishment of a beating car in 
June 2012, the number of registered users has reached 400 million, covering more than 400 cities, registering 17.5 million drivers, and peak daily orders exceeding 20 million. Therefore, this high demand travel mode has effectively stimulated the growth of employment.

Thirdly, the service quality of the car-hailing is better. At present, the service of the car-hailing has greatly improved compared to the traditional taxi service. Passengers can automatically check the driver's identity information, prices, route maps and real-time location simply by pre-reserving the car-hailing platforms, which effectively eliminates the problem of drivers circumventing passengers. In addition, when the passengers have finished the order transaction, the system will automatically appear service evaluation system, which will help improve the service of the car-hailing, and also play an important role in the prevention of security issues.

\section{The Basic Theory of the Car-Hailing}

The appearance of the car-hailing has aroused enthusiastic response from all walks of life, and people are paying more and more attention to the development status and future trends of the car-hailing. Therefore, there is a need for theoretical support in the formulation, implementation, and operation of the car-hailing policy. Regulatory arbitrage, authority and financial power, and sharing economy have all provided a strong theoretical basis for the car-hailing, which has led to a more standardized and legal development of car-hailing.

Firstly, the existence of regulatory arbitrage. At present, the academic community has not yet formed an internationally recognized definition of regulatory arbitrage. The common regulatory arbitrage mainly refers to the different financial institutions providing the same products, which are subject to supervision by different regulators, resulting in inconsistencies in rules, standards, and enforcement practices. As a result, financial institutions try to change their generics in order to place themselves in regulatory standards. The car-hailing are mainly restricted by the central government, local governments, car-hailing platforms, private car owners, and taxi companies. Therefore, the car-hailing have also been supervised by different supervisors. However, in the process of supervision, it still faces severe problems such as high supervision costs, low supervision efficiency, and insufficient supervision. Local governments are faced with the drawback of excessively high supervision costs in the process of supervision of car-hailing. On the one hand, local governments must not only consider local economic development levels, the number of urban traffic jams, the number of taxis, environmental carrying capacity and other factors, but also establish dynamic monitoring and adjustment mechanisms to create a good traffic environment. On the other hand, the above mentioned various factors all require a large amount of funds to fill the plight of car-hailing supervision. As a result, local governments, car-hailing platforms, and other related departments will all reduce the regulatory costs of car-hailing, or evade control to obtain dif- 
ferent excess returns.

Secondly, the right to determine the financial power. According to the Guiding Opinions on Deepening the Reform and Promoting the Healthy Development of the Taxi Industry and the Interim Measures for the Administration of Network Appointment of Taxi Business Services, the clear rules on car-hailing have given local governments greater autonomy. The "Provisional Measures" embodies the spirit of "simplifying administration, delegating power, integrating and optimizing services," and is another test of the level of local government governance. Therefore, the jurisdiction of the local government on the network about the car belongs to territorial management. The local government can, according to the actual conditions, adjust measures to local conditions and implement in-town measures, and comprehensively consider various factors, and reasonably determine the operating period of the car-hailing, so that car-hailing can provide better services for passengers. Regarding the determination of property rights, local governments should actively respond to the policies formulated by the central government and at the same time be subject to various influences from the central government. On the one hand, the central government encourages local governments to have greater autonomy over the Internet. The central government can subsidize local governments through fiscal transfer payments, effectively alleviating the pressure on local government finances. On the other hand, local governments can consider thel situation in the local area, make a reasonable calculation of the price of the car-hailing, increase the access threshold for the online market, and reduce the regulatory cost of the car-hailing. As a result, local governments are in a dominant position in the financial power of the government and make a great contribution to the promotion of local economic development and social harmony and stability.

Finally, sharing economic theory. The "sharing economy" is the topic that government supervision cannot avoid and should respond positively. The promulgation of the car-hailing is undoubtedly a typical form of the sharing economy. The "shared economy theory" can be traced back to the 1970s. The economic model proposed by Prof. Weitzman as an alternative to the existing wage system is the sharing economy. At present, under the background of the "Internet +" era of big data, with the continuous development of Internet technologies, more and more industries are developing with the help of Internet platforms, which has effectively promoted China's economic development. At the same time, it has had a certain impact on the real economy of our society. With the advent of the "resources sharing" of surplus resources, the network appropriation car provides a more convenient way for urban citizens to travel in China through the combination of advanced Internet technologies. Today, consumers use of the car-hailing has exceeded the "sharing economy" that Professor Weitzman originally expected. This result is mainly due to the constant changes in the values of urban residents in China, the increase in environmental awareness, and the rapid development of new platforms. Therefore, consumers can 
make reservations for car-hailing based on smartphone software. This sharing economy can develop rapidly and more conducive to the economic development of local governments.

\section{Local Governments Face Challenges in the Process of Monitoring Car-Hailing}

In addition to responding to the policies formulated by the central government, local governments in China must also make relevant countermeasures based on local conditions. However, in the process of local government supervision, there will still be multi-party games between the local government and the central government, local government and car-hailing platforms, local government and taxi companies, and local governments and private owners cars. On the one hand, local governments must support the encouragement of the development of new industries, and on the other hand, they must also solve the problems emerging in the development of emerging industries. The advent of car-hailing effectively examines the level of governance of local governments and measure of the relationship between the government and the market. As a result, the difficulty of monitoring the car-hailing has gradually increased, and the scope of supervision has gradually widened and supervision has improvement.

1) Local government and central government

Firstly, the policy objectives are different. There are some differences between the local government and the central government in the formulation of the policy goals of the network. The central government is mainly to safeguard the fundamental interests of the broad masses of the people. For the broad masses of the people, the appearance of the car-hailing has effectively stimulated the traditional taxi industry, forming a favorable competition which is conducive to improving the service quality of the network and taxis, and ultimately benefiting the passengers. And the central government is actively promoting the concept of innovation and entrepreneurship sharing and development. As a newly emerging industry, it is naturally supported by the central government. In addition to respecting the legislative authority of the central government, local governments must fully consider the situation in the local and consider factors such as population, urban traffic congestion, environmental carrying capacity, taxi companies, etc, and adjust measures to local conditions. Only by this way can we promote the development of local governments.

Secondly, the influence of financial power. The central government has given the local governments greater autonomy to regulate the car-hailing, and it has also affected the development of local economies in terms of financial power. Due to the multiple influences of geographical environment, demographic factors and historical reasons in our country, the development of each region is in an unbalanced state. The central government can use fiscal transfer payments to subsidize local governments to reduce the regulatory costs of local governments. In the process of supervision, local governments have seen problems such as in- 
creasing the scope of supervision, increasing difficulty in supervision, and increasing supervision, which eventually led to higher and higher supervision costs. Local governments face important difficulties in the financial crisis.

2) Local government and car-hailing platform.

Firstly, the price is set. With the continuous development of Internet technology, the emergence of smart phones has gradually changed people's values and ideology. The car-hailing platform uses a smart phone to create its own car-hailing platform for consumers to download. In the process of consumers use, the online tour car platform will provide consumers with driver's identity information, real-time routes, and pricing miles to facilitate passengers' travel. However, according to Article 3, paragraph 2, of the Interim Measures for the Administration of Online Booking of Taxi Operating Services, "The online tour price shall be adjusted by the market, unless the city's people's government deems it necessary to implement the government guidance price". Therefore, the "Provisional Measures" clearly stipulates that the car-hailing should be market-based, but they still delegate power to the local governments to implement governmentguided pricing of car-hailing.

Secondly, improving the access threshold. Due to the continuous development and improvement of the car-hailing, its operating model has gradually entered formality. As the entry threshold to the market is very lowly, more and more social idle resources begin to enter the industry, and the number of car-hailing is increasing, causing urban traffic congestion. In addition, the quality of drivers and the problems of disputes and accidents during the travel process have also attracted the attention of local governments. Therefore, the local government has put forward more conditions for access to vehicles and drivers in the car industry. On the one hand, it can improve the service quality of the network and meet the diversified passenger demand of different people; on the other hand, it also plays a positive role in the personal safety of consumers. In addition, the local government controls the number of licenses on the network to reduce the traffic congestion in the city and reduce the pressure on the environment.

3) Local Governments and Taxi Companies

Since the Reform and opening up, China's political, economic, and cultural development has a great improvement, and the number of taxis in China has also increase. In 1995, the Urban Road Traffic Planning and Design Code issued by the Ministry of Housing and Urban-Rural Development had a guideline for the number of urban taxis not less than 2 vehicles per 1000 people in big cities; not less than 0.5 vehicles per 1000 people in small cities Medium-sized cities can take their value between them. According to this, the number of people in major cities should not be less than 20 vehicles. The number of people in small cities should not be less than 5 vehicles. However, traditional taxis now face a grim situation. After more than two decades of development, the emergence of new modes of transportation, such as buses and subways, has exerted a powerful impact on the traditional taxi industry. Relying on traditional street parades to soli- 
cit guests has lost its competitiveness, and it has been unable to meet the demand for popular travel, and the traditional quality of taxi service lags behind that of the Internet, and taxi drivers also appear to detour and smash off passengers. Such problems make the public tend to prefer to make appointments when traveling. How to protect the traditional taxi industry from the challenges of emerging industries and promote the stable development of the taxi industry has become a grim problem that the government needs to solve.

4) Local Governments and Private Car Owners

Prior to the advent of the car-hailing, there have been some phenomena involving private cars carrying passengers, which are very different from those of regular taxis. They are characterized by high fees and cheating. The advent of car-hailing platforms will allow these private car owners to have a smooth channel for their interests. With the increase in the number of private cars entering the car-hailing platforms, the threshold for entry into the market is relatively low, and thus the quality of drivers with uneven identities has appeared, it has limited the service level and service quality of online car services. On the one hand, it is a more tolerant attitude towards private car owners engaged in car-hailing service. If the owner of a private car is not allowed to work part-time in a car-related business, the advantages of a car-based car will be greatly reduced. On the other hand, local governments have adopted a more rigorous attitude toward private car owners. By restricting the number of cars in private cars, the access threshold for private cars will gradually increase. Private car owners will appeal to local governments for their own aspirations, and local governments will also comprehensively consider making corresponding regulations to solve the problems of private car owners.

Therefore, local governments often face the above challenges in the process of monitoring the car-hailing. For each department, the government must not only measure its own development and interests, but also consider the drawbacks brought about by it. How the local government finds suitable local development strategies, how to control the network about the car platform, how to protect the traditional taxi companies, and the attitude taken by owners of private cars have become problems that local governments urgently need to solve.

\section{Local Government's Supervision of Car-Hailing}

Asking into consideration the challenges faced by local governments as mentioned above, in order to achieve healthy and sustainable development of the car-hailing industry, the state has issued corresponding laws and regulations as the bottom line of behavior. The establishment of a regulatory system within the industry and the use of scientific and technological means to improve the regulatory means have become a reality. The car-hailing is an important task for the car industry [3]. However, under the circumstances that local governments have been given greater autonomy, local governments can improve the supervision of car-hailing has become a great concern to the community. 
1) Adhere to the legislative authority of the central government

As local governments, on the one hand, they must not only respond positively to the policy goals set by the central government in relation to the car-hailing, but also respect the legislative authority of the central government. The Interim Measures for the Administration of Online Booking of Taxi Business Services stipulates that urban people's governments must implement government guidance prices and can implement government guidance prices. However, the principle of "Interim Measures for the Management of Online Booking of Taxi Business Services" establishes itself as an exception to the fact that the online auction vehicles are market-based, with the exception of government-guided prices. If local governments formulate supporting implementation rules, most of them implement the government-instruction pricing mechanism for government-subsidized car-hailing tariffs, making the policies formulated by the central government useless, and the car-hailing will become a mirage that only stays on central documents. Once this happens, it will greatly damage the authority of the central authorities and violate the basic national system of our country [4]. Therefore, the local government must respect the central government's legislative authority sufficiently and maintain the authority of the relevant central government departments. It will effectively apply the implementation rules of the car-hailing in combination with local realities to promote local development.

2) Adhere to the policy objectives of local governments

The promulgation of the car-hailing has brought a severe test to the governance of the local government. As the public agency representing the interests of the broadest masses of the people, local governments must always uphold the goal of the supremacy of the interests of the people. The existence of incentive competition between online dating vehicles and traditional rental has effectively improved the service quality of car-hailing and traditional taxis, and ultimately benefited the general public. On the one hand, local governments not only implement the central government's legislative policies, but also implement them in detail. On the other hand, local governments must always adhere to the local economic development and take into account various factors such as the city's level, traffic congestion, environmental carrying capacity, and public opinion. A detailed formulation of the implementation rules for the local development of the network about the car, the local government in conjunction with local transportation departments, local industrial and commercial bureaus and other departments, through the development of effective measures to gradually eliminate the traditional taxi industry and the network about the car industry competition. The local government has always adhered to the local strategy for sustainable development and implemented the car-hailing policy that suits local development. Only in this way can the positive image of the government be established and the authority of the government can be maintained.

3) Development of a "political plus enterprise" car-hailing regulatory mode

With the continuous improvement and development of the car-hailing sys- 
tem, the government has focused on the development of the traditional taxi industry. However, there is a certain degree of particularity in the car-hailing, and the government should treat it differently. On the one hand, the government could not control the car-hailing as much as the number of taxis was strictly controlled, and the local government relaxed the conditions for entering the car-hailing. Due to the large number of private cars, local governments must increase the supervision of private cars through manpower, material resources, and financial resources, which put local governments under enormous financial pressure. Local governments should cooperate with these enterprises in a timely manner. Through the establishment and improvement of relevant regulatory platforms, the effective integration of car-hailing resources will enable local government regulators and corporate personnel to obtain relevant information in a timely, rapid and accurate manner, and constantly improve the construction of the car-hailing platforms.

4) Strengthening Legislation to Eliminate the Drawbacks of Local Legislation

In the process of supervising the car-hailing, there are loopholes in the supervision of local governments, so the car-hailing platforms and various departments will be available for drilling. Therefore, local governments should first strengthen legislation to eliminate legislative abuses, continuously improve relevant laws and regulations, formulate detailed rules for the enforcement of online vehicles, and eliminate the occurrence of unlawful acts. Secondly, we can strengthen cooperation and coordination among various departments, and local governments should strengthen Local industry and commerce bureaus, local transportation departments and other multi-sector contacts are actively and steadily advancing the reform of the car-hailing system to jointly promote the standardized development. At the same time, all departments should respect the laws of the market regarding the regulation of car-hailing. Carry about the healthy development of the car, strengthen the guiding role of the market [5], recognize the relationship between the government and the market, the central government and the local government, the local government and car-hailing platforms, local government and taxi companies, and improve the relevant laws to promote the network more standardized car Development.

\section{Conclusions}

China's political, economic and cultural development has been improvement, government functions have also changed accordingly. The traditional regulatory model has been unable to effectively solve the existing problems. If we adhere to the regulatory concept of sticking to the orders, we will lose our advantages in the car-hailing. The problems of previous taxis, expensive taxis and poor service quality will continue to exist. The local government should continue to improve and develop the car-hailing policy, adhere to the goal of promoting innovation, create a new concept of administrative regulation, and strengthen exchanges and cooperation among various departments. In addition, local governments should 
also promote the development of car-hailing by adhering to the authority of the central government, adhering to the objectives of local policies, setting up a "political-enterprise" regulatory model, and strengthening relevant laws and other related reform measures.

From the perspective of policy networks theory, this paper studies the current situation of local government supervision of car-hailing, analyzes the problems existing in the interaction process of car-hailing supervisory actors, and proposes suggestions for optimizing and improving online dating policies. Through research, it has been found that the policy networks can effectively explain the issue of the car-hailing policy networks. At the same time, the policy networks theory can provide the validity of the car-hailing policy formulation. However, some scholars in the domestic research policy networks theory have proposed the applicability of the policy networks theory. For this reason, this study has not been discussed here.

Basing on the theory of policy networks, this study analyzes the interactions among online policy drivers and obtains some meaningful research results. However, due to the limitation of time and effort, there are still some issues to be studied. First of all, without in-depth investigation and research, real data and some actual conditions may not be reflected in the research and analysis, resulting in bias in the research conclusions; secondly, the local government's online car-hailing policy documents collected by this study do not fully include the local governments of the country. The online car-hailing policy has resulted in limited applicability of research findings.

\section{References}

[1] Li, Y. (2016) Analysis and Avoidance of Network Security Risks on Vehicles. Journal of Hubei Institute of Science and Technology, 8, 10.

[2] Pan, L. (2016) Study on the Countermeasures of Local Government's Supervision and Management of Vehicles. Dongbei University of Finance and Economics.

[3] Zhang, X.N. (2016) The Regulatory Improvement and Prospects of Online Dating Industry. Enterprise Reform and Management, 17, 59.

[4] Zhang, X.Y. (2016) A Study on Some Legal Issues in Local Legislation of Internet Vehicles. Administration and Law, 10, 87-93.

[5] Wang, J. (2016) The Regulatory Dilemma and Settlement of China's Network about Vehicles. Administrative Law Studies, 2, 50. 